\title{
ChemComm
}

Unprecedented tin iodide perovskite-like structures featuring ordering of organic moieties

\begin{tabular}{|r|l|}
\hline Journal: & ChemComm \\
\hline Manuscript ID & CC-COM-01-2020-000549.R1 \\
\hline Article Type: & Communication \\
\hline & \\
\end{tabular}

SCHOLARONE ${ }^{\text {m }}$

Manuscripts 
Received 00th January 20xx, Accepted 00th January 20xx DOI: $10.1039 / \times 0 \times x 00000 x$

\section{Unprecedented tin iodide perovskite-like structures featuring ordering of organic moieties}

\author{
Jason A. McNulty a and Philip Lightfoot ${ }^{* a}$
}

Two unique hybrid tin iodides, with generic compositions $A_{0.5} A^{\prime}{ }_{0.5} \mathrm{Snl}_{3}$ and $A_{1.5} A^{\prime}{ }_{0.5} \mathrm{Snl}_{4}$ have been prepared. Each shows ordering of the two organic moieties ( $A$ and $\left.A^{\prime}\right)$ on distinct crystallographic sites, leading to novel 3D and 2D structure types, respectively.

In recent years there have been a significant number of studies regarding organic-inorganic hybrid halide perovskites and the use of these materials for various applications. ${ }^{1-3}$ Many of these studies have focused primarily on the synthesis of lead-based materials due to their high photovoltaic efficiency ${ }^{4-6}$ and have resulted in a wide variety of crystal structures including $3 D^{7}$ and lower dimensional layered perovskites ${ }^{8}$ (with the (110)oriented perovskites of particular interest to the present work). ${ }^{9,10}$ Both $3 D\left(A B X_{3}\right)$ and (110)-oriented layered $\left(A A^{\prime} B X_{4}\right)$ perovskites $(A=$ organic or inorganic monovalent cation, $B=$ $\mathrm{Pb}^{2+}$ or $\mathrm{Sn}^{2+}, \mathrm{X}=\mathrm{Cl}, \mathrm{Br}$ or I) contain corner-linked $\mathrm{BX}_{6}$ octahedra. However, the $3 \mathrm{D}$ network in the (110) structures is disrupted, i.e. the 3D perovskite structure can be described as being sliced across an octahedral edge, resulting in layers of corner-linked $\mathrm{BX}_{6}$ octahedra separated by $\mathrm{A}$ and $\mathrm{A}^{\prime}$ cations. In our previous work, ${ }^{11}$ we presented two new examples of (110)-oriented layered structures featuring ordering of two distinct organic moieties, namely $(\mathrm{ImH})(\mathrm{GuH}) \mathrm{PbBr}_{4}$ and $(\mathrm{TzH})(\mathrm{GuH}) \mathrm{PbBr}_{4}\left(\mathrm{ImH}^{+}\right.$ = imidazolium, $\mathrm{GuH}^{+}=$guanidinium, $\mathrm{TzH}^{+}=1,2,4$-triazolium). In these materials we suggested that ordering of the organic cations is driven by ionic size effects and hydrogen-bonding factors. This is shown by the preference of $\mathrm{GuH}^{+}$for different sites in each material (intra-layer and inter-layer sites, respectively). This different structural behaviour suggests a potentially diverse range of related target materials.

The rich structural and compositional flexibility of lead halide perovskites has contributed to their continued study.

a. School of Chemistry and EaStChem, University of St Andrews, St Andrews, Fife, KY16 9ST, UK. E-mail: pl@st-andrews.ac.uk

† Electronic Supplementary Information (ESI) available: Synthesis, single crystal Xray diffraction, distortion mode analysis, crystallographic data (CIF). CCDC 1969685 (1) \& 1969686 (2).
However, due to the high toxicity of $\mathrm{Pb}$, investigations into the replacement of this with less toxic elements such as $\mathrm{Sn}$ or $\mathrm{Ge}$ is of paramount importance. ${ }^{12}$ While examples of hybrid perovskites containing each of these alternatives is known, Ge halide perovskites seem less promising due to the poor chemical stability of $\mathrm{Ge}^{2+} .{ }^{13} \mathrm{Sn}$-based perovskites are more desirable however, due to their similar electronic and optical properties to $\mathrm{Pb}$ perovskites and the eco-friendly degradation product, $\mathrm{SnO}_{2} \cdot{ }^{14,15}$

In this paper we present two new hybrid Sn iodide perovskites inspired by our previous work on $\mathrm{Pb}$ bromide perovskites. Our nominal target compositions were $\mathrm{AA}^{\prime} \mathrm{Snl}_{4}$, containing two distinct organic moieties, $A$ and $A^{\prime}$. To our surprise the reactions produced two novel structure types each showing unusual structural features which would have been difficult to predict, viz., the 2D (110)-oriented layered perovskite $(\mathrm{GuH})_{1.5}(\mathrm{Me}-\mathrm{ImH})_{0.5} \mathrm{Snl}_{4} \quad\left(\mathrm{Me}-\mathrm{ImH}^{+}=1-\right.$ methylimidazolium) and the 3D perovskite $(\mathrm{GuH})_{0.5}(\mathrm{TzH})_{0.5} \mathrm{Snl}_{3}$.

Details of synthesis and characterisation are provided in ESI. The crystal structures of $(\mathrm{GuH})_{1.5}(\mathrm{Me}-\mathrm{ImH})_{0.5} \mathrm{Snl}_{4} \quad(\mathbf{1})$ and $(\mathrm{GuH})_{0.5}(\mathrm{TzH})_{0.5} \mathrm{Snl}_{3}(\mathbf{2})$ were determined by single crystal X-ray diffraction at $173 \mathrm{~K}$ : crystallographic details given in Table 1 . Fig. 1 shows the crystal structure of 1 at $173 \mathrm{~K}$, in comparison to that of the previous, related example $(\mathrm{ImH})(\mathrm{GuH}) \mathrm{PbBr}_{4}$ at $93 \mathrm{~K} .{ }^{11}$ For
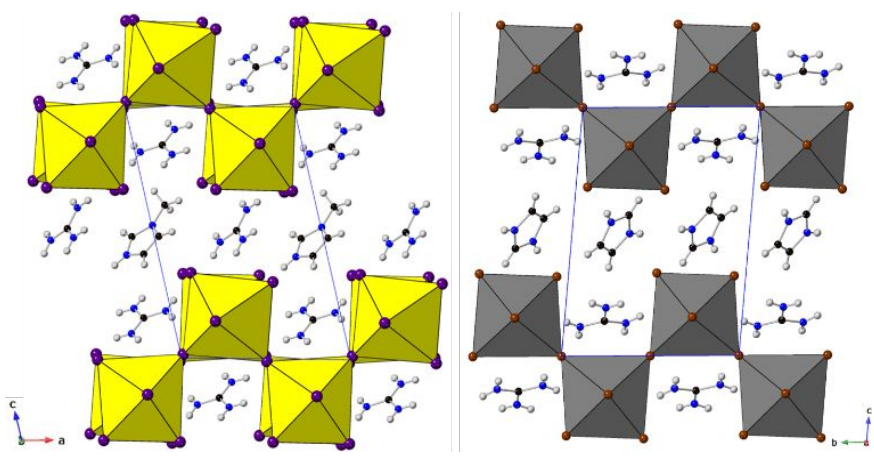

Figure 1 Crystal structure of (left) 1 at $173 \mathrm{~K}$ and (right) (ImH)(GuH) $\mathrm{PbBr}_{4}$ at $93 \mathrm{~K}^{11}$. Note the different nature of 'staggering' of neighbouring perovskite-like layers, due to the accommodation of ' 3 to 1 ' rather than ' 2 to 2 ' inter-layer ordering. 
Table 1 Crystallographic data and refinement details for $\mathbf{1}$ and $\mathbf{2}$, at $173 \mathrm{~K}$.

\begin{tabular}{|l|l|l|}
\hline & \multicolumn{1}{|c|}{$\mathbf{1}$} & \multicolumn{1}{c|}{$\mathbf{2}$} \\
\hline Formula & $\mathrm{C}_{7} \mathrm{~N}_{11} \mathrm{H}_{25} \mathrm{Sn}_{2} \mathrm{I}_{8}$ & $\mathrm{C}_{3} \mathrm{~N}_{6} \mathrm{H}_{10} \mathrm{Sn}_{2} \mathrm{I}_{6}$ \\
\hline Formula weight & 1515.96 & 1128.95 \\
\hline Density/g cm${ }^{-3}$ & 3.08 & 3.591 \\
\hline Crystal system & Triclinic & Tetragonal \\
\hline Space group & $P-1$ & $P 4_{3} 2_{1} 2$ \\
\hline$a / \AA$ & $9.3530(7)$ & $9.0746(6)$ \\
\hline$b / \AA$ & $12.8318(9)$ & $9.0746(6)$ \\
\hline$c / \AA ̊$ & $15.0588(11)$ & $25.3561(18)$ \\
\hline$\alpha /^{\circ}$ & $111.452(3)$ & 90 \\
\hline$B /{ }^{\circ}$ & $102.192(3)$ & 90 \\
\hline$\gamma /{ }^{\circ}$ & $91.234(3)$ & 90 \\
\hline $\mathrm{V} / \AA^{\circ}$ & $1634.4(2)$ & $2088.0(3)$ \\
\hline $\mathrm{Z}$ & 2 & 4 \\
\hline Measured ref & 16872 & 20972 \\
\hline Independent ref & $7442[R($ int $)=0.0315]$ & $2382[R($ int $)=0.0754]$ \\
\hline Refined parameter & 254 & 78 \\
\hline $\mathrm{GOOF}$ & 1.017 & 1.047 \\
\hline $\begin{array}{l}\text { Final R indices }(I> \\
2 \sigma(I))\end{array}$ & $R_{1}=0.0263$, & $R_{1}=0.0239$, \\
\hline
\end{tabular}

clarity, disorder around the $\mathrm{GuH}^{+}$site in $(\mathrm{ImH})(\mathrm{GuH}) \mathrm{PbBr}_{4}$ has been omitted. It can be seen that the structure of 1 features

several significant differences. Unlike in both our previously described materials, where $\mathrm{GuH}^{+}$occupies either intra- or interlayer sites preferentially, in a 1:1 ratio with the second organic cation, in this case the 3:1 ratio leads to $\mathrm{GuH}^{+}$occupying both intra- and inter-layer sites simultaneously. This dual site occupancy has an additional effect that in order to optimise hydrogen bonding, the layers of corner-linked $\mathrm{BX}_{6}$ octahedra no longer remain aligned in the same manner previously reported for (110)-oriented layered perovskites. This change results in a previously unseen " 3 to 1 " inter-layer spacing compared to the previously seen " 2 to 2 " type.

While there have been numerous studies regarding mixed A-site occupancy in $\mathrm{ASnl}_{3}$ perovskites, most of these have focused on the use of $\mathrm{FA}^{+}, \mathrm{MA}^{+}$and $\mathrm{Cs}^{+}$( $\mathrm{FA}=$ formamidinium, $\mathrm{MA}=$ methylammonium). ${ }^{14,16-18}$ Many of these known $\mathrm{ASnl}_{3}$ perovskites feature octahedral tilting to optimise bonding and

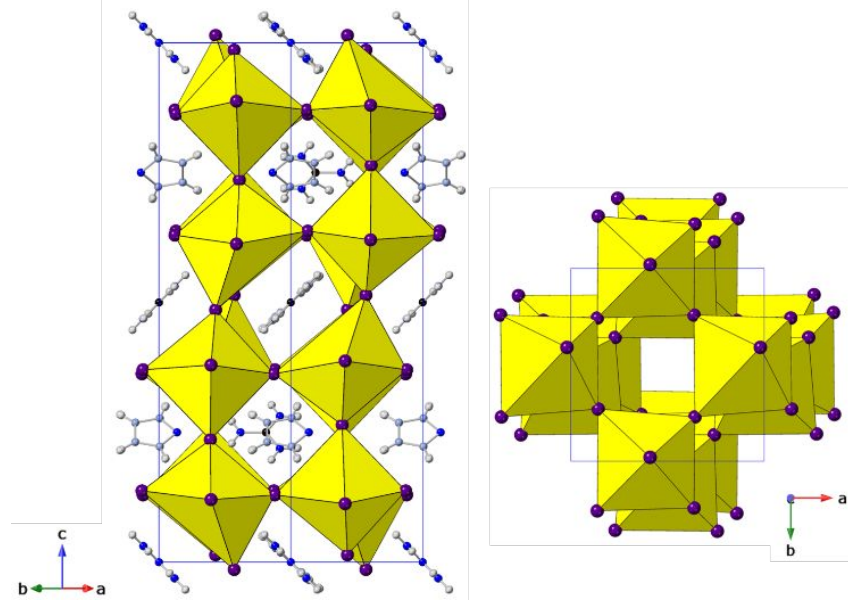

Figure 2 Crystal structure at $173 \mathrm{~K}$ of 2 viewed along (left) 110-direction and (right) along the $c$-axis. Note the significant distortion of the $\mathrm{SnI}_{6}$ octahedra. accommodate the A-site cations. The crystal structure of $\mathbf{2}$ is shown in Fig. 2 and differs significantly from the known mixed A-site tin halides in that there is no rotation of $\mathrm{SnI}_{6}$ octahedra, but instead the octahedra are considerably distorted. While $\mathrm{GuH}^{+}$and $\mathrm{TzH}^{+}$occupy crystallographically distinct sites throughout the structure there remains local disorder on each of the organic cation sites at $173 \mathrm{~K}$; for clarity only one orientation is shown in Fig. 2. The A-site ordering, coupled with co-operative octahedral distortions, leads to a chiral supercell $a$ $\sim \sqrt{2} a a_{\mathrm{p}}, \mathrm{c} \sim 4 a_{\mathrm{p}}$, relative to the aristotype cubic perovskite subcell, $a_{\mathrm{p}}$. Supercells based on quadrupling (or higher order multiples) of the aristotype perovskite unit cell are rare, and are usually related to octahedral tilting effects. ${ }^{19}$ The mechanism in $\mathbf{2}$ is clearly distinct from this, and appears to be a unique variation.

In our previous work, ${ }^{11}$ we reported that $\mathrm{GuH}^{+}$and $\mathrm{TzH}^{+}$are of a similar size (effective ionic radii 2.66 and $2.68 \AA$, respectively), while $\mathrm{ImH}^{+}$is only marginally larger $(2.74 \AA$ ) and we argued that the cation ordering in $(\mathrm{GuH})(\mathrm{TzH}) \mathrm{PbBr}_{4}$ and $(\mathrm{ImH})(\mathrm{GuH}) \mathrm{PbBr}_{4}$ is driven by both ionic size and hydrogenbonding effects. Although $\mathrm{Me}-\mathrm{ImH}^{+}$was not included in our previous work it can be assumed that due to the replacement of $-\mathrm{H}$ with a $-\mathrm{Me}$ group that this moiety is larger in size than $\mathrm{ImH}^{+}$. This suggests that, like $I \mathrm{mH}^{+}$, the size of $\mathrm{Me}-\mathrm{ImH}^{+}$ precludes the occupancy of the intra-layer "perovskite-like"

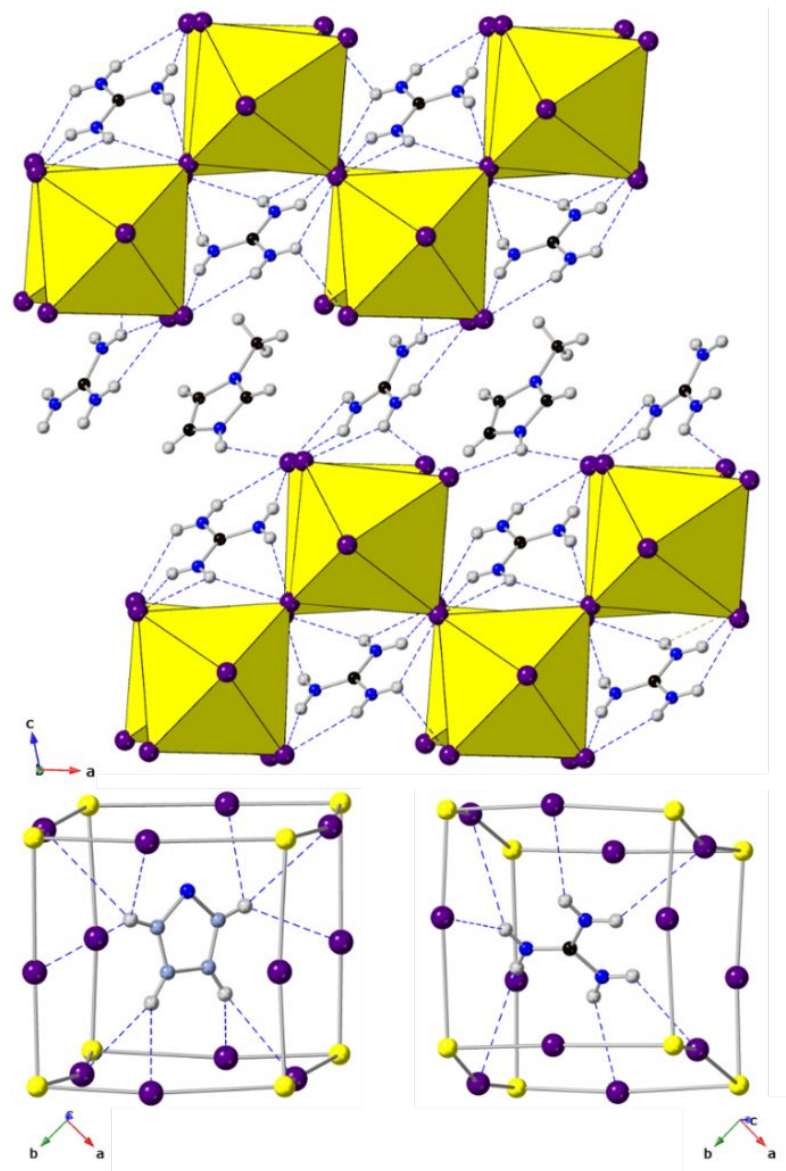

Figure 3 Hydrogen bonding environment for (top) 1 and around $\mathrm{TzH}^{+}$(bottomleft) and $\mathrm{GuH}^{+}$(bottom-right) in 2. Only one orientation of the $\mathrm{GuH}^{+}$moiety in $\mathbf{1}$ is shown for clarity. Note the limited $\mathrm{H}$-bonding of $\mathrm{Me}-\mathrm{ImH}^{+}$in the intra-layer site in 1. 
site, and subsequently only $\mathrm{GuH}^{+}$occupies this site in $1 . \mathrm{GuH}^{+}$ also occupies half of the inter-layer sites, likely as a consequence of the limited $\mathrm{H}$-bonding capacity of $\mathrm{Me}^{-} \mathrm{ImH}^{+}$ compared to $\mathrm{ImH}^{+}$. While $\mathrm{Me}-\mathrm{ImH}^{+}$is only capable of $\mathrm{H}$-bonding through a single $\mathrm{N}-\mathrm{H}$ donor there are six available in $\mathrm{GuH}^{+}$. The enhanced $\mathrm{H}$-bonding options in $\mathrm{GuH}^{+}$provide stabilisation between perovskite layers, whereas the $\mathrm{H}$-bonding of $\mathrm{Me}-\mathrm{ImH}^{+}$ is highly directional and limited, and does not contribute significantly towards inter-layer stabilisation, as shown in Fig. 3.

A similar approach was used to understand the structure adopted by 2 . Due to the similarity in size of $\mathrm{GuH}^{+}$and $\mathrm{TzH}^{+}$it is reasonable that both cations can be incorporated simultaneously, however the calculated tolerance factors ( $t=$ 1.08 and 1.09 for $\mathrm{GuH}^{+}$and $\mathrm{TzH}^{+}$, respectively) are higher than the compositional limit suggested by Travis et al. for hybrid iodide perovskites $(t \leq 1.06)^{20}$ and therefore it is perhaps surprising that a 3D perovskite structure has been formed. The adoption of the perovskite structure may be linked with the presence of the stereochemically active lone pair on $\mathrm{Sn}^{2+}$. The inert pair effect in this example leads to a greater octahedral distortion than has been seen in previous tin iodides (see below), thus allowing the successful incorporation of the larger than expected organic cations. Both cations are capable of several $\mathrm{H}$-bonding options, shown in Fig. 3, further stabilising the considerable distortion of the $\mathrm{SnI}_{6}$ octahedra and likely resulting in the observed cation ordering throughout the structure. The presence of disorder on both cation sites likely enhances the number of $\mathrm{H}$-bonding options and subsequently contributes to the $\mathrm{Snl}_{3}$ framework stabilisation.

Comparison of the structural distortions of both of the present compositions to previously reported materials is important in attempting to understand the structural behaviour exhibited. The mean distortion level $(\Delta \mathrm{d})$ and bond angle variance $\left(\sigma^{2}\right)$ of each octahedron in both compositions were calculated (details are provided in ESI) and the values shown in Table 2. While the mean distortion level in $\mathbf{1}$ is considerably larger than the (110) layer type $\mathrm{Pb}$-based materials we reported recently, these are still somewhat similar to those in $(\mathrm{GuH})_{2} \mathrm{Snl}_{4}$, suggesting that in general the distortion levels in Sn-based (110)-oriented structures are considerably larger than in related $\mathrm{Pb}$-based materials. There does however, still remain a reasonably large difference in one of the $\mathrm{Snl}_{6}$ octahedra between $(\mathrm{GuH})_{2} \mathrm{Snl}_{4}$ and $\mathbf{1}$, likely a result of the limited $\mathrm{H}$ bonding capacity of $\mathrm{Me}-\mathrm{ImH}^{+}$providing less stabilisation to the structure compared to $\mathrm{GuH}^{+}$.

In contrast, comparison of the known $\mathrm{ASnl}_{3}$ materials to the distortions present in $\mathbf{2}$ indicates a much more significant difference between structures. In all of the known structures the degree of distortion in the bond lengths and bond angle variance is relatively small, however in $\mathbf{2}$ these are drastically larger. These enlarged distortion values are likely linked to the absence of octahedral tilting in $\mathbf{2}$ normally observed in $\mathrm{ASnl}_{3}$ perovskites. On the contrary, the structural flexibility necessary to accommodate the large A-site in $\mathbf{2}$ arises from the higher degree of distortion of the $\mathrm{Snl}_{6}$ octahedron, due to the lonepair. The $\mathrm{SnI}_{6}$ octahedron in $\mathbf{2}$ displays three short and three
Table 2 Summary of calculated tolerance factors $(t),{ }^{a}$ bond length distortions $(\Delta d)$ and bond angle variance $\left(\sigma^{2}\right)$ for compounds reported here and in literature.

\begin{tabular}{|l|l|l|l|l|}
\hline Perovskite type & $\begin{array}{l}\text { Species in } \\
\text { perovskite-like ' } \mathrm{A}^{\prime} \\
\text { site }\end{array}$ & $t^{b}$ & $\Delta \mathrm{d}\left(\times 10^{-4}\right)$ & $\sigma^{2}$ \\
\hline$(110)$-oriented: & & & & \\
\hline$(\mathrm{ImH})(\mathrm{GuH}) \mathrm{PbBr}_{4}{ }^{11}$ & $\mathrm{GuH}^{+}$ & 1.04 & 7.39 & 16.16 \\
\hline$(\mathrm{TzH})(\mathrm{GuH}) \mathrm{PbBr}_{4}{ }^{11}$ & $\mathrm{TzH}^{+}$ & 1.04 & 10.97 & 28.22 \\
\hline$(\mathrm{GuH})_{2} \mathrm{Snl}_{4}{ }^{9}$ & $\mathrm{GuH}^{+}$ & 1.08 & 35.37 & 11.41 \\
\hline & & & 30.49 & 19.18 \\
\hline $\mathbf{1}$ & $\mathrm{GuH}^{+}$ & 1.08 & 34.30 & 11.22 \\
\hline & & & 45.71 & 15.35 \\
\hline $3 \mathrm{D}:$ & & & & 1.18 \\
\hline $\mathrm{CsSnl}{ }_{3}^{16}$ & $\mathrm{Cs}^{+}$ & 0.91 & 0.01 & 1.30 \\
\hline $\mathrm{MASnl}_{3}{ }^{14}$ & $\mathrm{MA}^{+}$ & 1.01 & 1.01 & 0.67 \\
\hline $\mathrm{FASnl}_{3}{ }^{14}$ & $\mathrm{FA}^{+}$ & 1.04 & 1.45 & 71.45 \\
\hline $\mathbf{2}$ & $\left(\mathrm{GuH}_{0.5}(\mathrm{TzH})_{0.5}\right.$ & 1.09 & 81.25 & \\
\hline
\end{tabular}

${ }^{a}$ For a "cubic" perovskite $\mathrm{ABX}_{3}, t=\left(r_{\mathrm{A}}+r_{\mathrm{X}}\right) / \sqrt{ } 2\left(r_{\mathrm{B}}+r_{\mathrm{X}}\right) .{ }^{b}$ Radii used for organic moieties were taken from our previous work, ${ }^{11}$ radii for $\mathrm{Cs}^{+}$and $\mathrm{Pb}^{2+}$ from Shannon ${ }^{21}$ and radius for $\mathrm{Sn}^{2+}$ from Travis et al. ${ }^{20}$

much longer Sn-I bonds, with a 'facial' conformation of the short/long bonds. This is due to a significant contraction of one octahedral face (I---I contacts in the range 4.14 to $4.30 \AA$ ) and an enlargement of the opposite one (I---I ranging from 4.81 to $5.90 \AA$ ) rather than an 'off-centring' of the $\mathrm{Sn}^{2+}$ ion itself. This contrasts with the structural behaviour observed in several Ge iodide compositions ${ }^{22}$ where the stereoactive lone-pair on $\mathrm{Ge}^{2+}$ leads to off-centring of $\mathrm{Ge}^{2+}$, rather than such an extreme distortion of the octahedral iodide environment itself. Ball and stick representations of the $\mathrm{Snl}_{6}$ octahedra present in $\mathbf{1}$ and $\mathbf{2}$ are shown in Fig. 4, highlighting the significant distortions present.

Comparison of $\mathbf{2}$ to some known materials featuring octahedra with 'large' and 'small' faces, shown in Table 3, highlights the considerable octahedral distortion observed in this material. While $(\mathrm{GuH}) \mathrm{Snl}_{3}$ and $\mathrm{AzPbBr}_{3}$ are $6 \mathrm{H}$-hexagonal perovskites featuring face-sharing octahedra and are therefore expected to feature significant octahedral distortions of this type, the values calculated for $\mathbf{2}$ are considerably larger. The most similar distortion values are those calculated for " $\mathrm{LiO}_{6}$ " octahedra in $\mathrm{LiNbO}_{3}$. However, the $\mathrm{Li}$ environment in $\mathrm{LiNbO}_{3}$ is probably not simply octahedral, as it occupies the perovskite A-site, albeit with a considerable displacement. Hence, compared to many well-known perovskites containing polar octahedra, the distortion in $\mathbf{2}$ seems extreme.

Table 3 Calculated areas for large $\left(A_{L}\right)$ and small $\left(A_{S}\right)$ octahedral faces of known perovskite materials determined from octahedral edges, relative ratio between faces $\left(A_{L} / A_{s}\right)$, mean edge length $(s)$ and magnitude of the deviation in edge lengths $(\Delta s) .^{23}$

\begin{tabular}{|l|l|l|l|l|l|l|}
\hline Material & $\mathrm{BX}_{6}$ & $\mathrm{~A}_{\mathrm{L}} / \AA^{2}$ & $\mathrm{~A}_{\mathrm{S}} / \AA^{2}$ & $\mathrm{~A}_{\mathrm{L}} / \mathrm{A}_{\mathrm{S}}$ & $s / \AA$ & $\Delta s$ \\
\hline $\mathbf{2}$ & $\mathrm{Snl}_{6}$ & 13.49 & 8.92 & 1.47 & 4.709 & 0.486 \\
\hline$(\mathrm{GuH}) \mathrm{Snl}_{3}^{24}$ & $\mathrm{Snl}_{6}$ & 10.03 & 7.68 & 1.31 & 4.512 & 0.301 \\
\hline $\mathrm{AzPbBr}_{3}{ }^{25}$ & $\mathrm{PbBr}_{6}$ & 8.43 & 6.53 & 1.29 & 4.148 & 0.266 \\
\hline $\mathrm{PZT}^{625}$ & $\mathrm{BO}_{6}$ & 4.44 & 2.78 & 1.60 & 2.869 & 0.333 \\
\hline $\mathrm{LiNbO}_{3}{ }^{27}$ & $\mathrm{NbO}_{6}$ & 3.59 & 3.20 & 1.12 & 2.799 & 0.080 \\
\cline { 2 - 7 } & $\mathrm{LiO}_{6}$ & 4.89 & 3.20 & 1.53 & 3.041 & 0.322 \\
\hline
\end{tabular}

${ }^{a} \mathrm{Az}=$ azetidnium. ${ }^{b} \mathrm{PZT}$ has the composition $\mathrm{PbZr}_{0.58} \mathrm{Ti}_{0.42} \mathrm{O}_{3}$. 

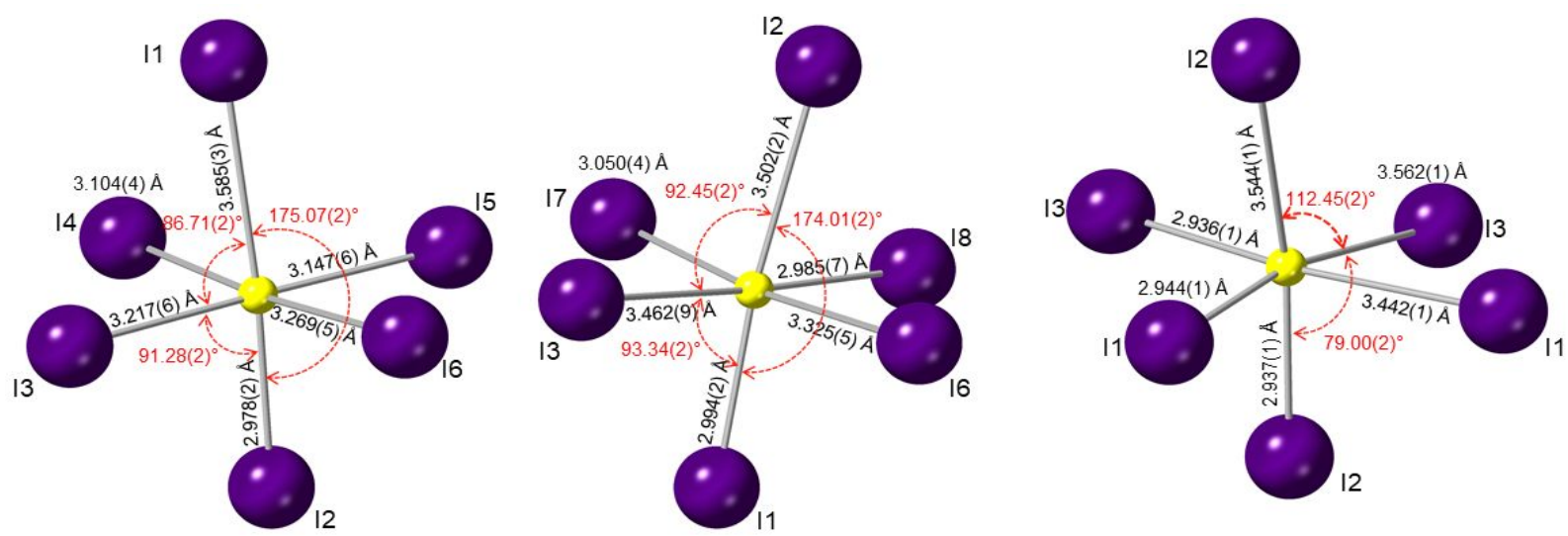

Figure 2 Ball and stick representations of the octahedra present in (left and middle) $\mathbf{1}$ and (right) $\mathbf{2}$ highlighting the significant distortion in both bond lengths and bond angles. Note the considerably distorted I2-Sn-13 bond angle present in $\mathbf{2}$.

In summary, we have prepared two new examples of tin halide perovskites featuring unprecedented ordering patterns of organic cations. In $(\mathrm{GuH})_{1.5}(\mathrm{Me}-\mathrm{ImH})_{0.5} \mathrm{Snl}_{4}$ we introduce a previously unseen ' 3 to 1 ' (110)-oriented layered structure with $\mathrm{GuH}^{+}$occupying both intra-layer and inter-layer sites simultaneously. Conversely, in $(\mathrm{GuH})_{0.5}(\mathrm{TzH})_{0.5} \mathrm{Snl}_{3}$ we present the first example of a 3D-hybrid perovskite featuring 1:1 A site cation ordering and an unusual supercell, mediated by octahedral distortions rather than octahedral tilting. The cationic ordering behaviour and subsequent structural distortions have been discussed in terms of ionic size effects, lone-pair effects and hydrogen-bonding environments. This work prompts further study of these interesting structure-types and the effect of different organic moieties on structure. Due to the air sensitivity of these materials, analysis of their physical properties has not yet been conducted, however it would be of interest to study how these unusual structural and compositional features affect the optical properties of these materials.

We acknowledge support from the University of St Andrews and the Leverhulme trust (RPG-2018-065). The research data supporting this publication can be accessed at https://doi.org/10.17630/dc6f127d-5e6d-4523-bd0acd24da3e9c06.

\section{Conflicts of interest}

There are no conflicts to declare.

\section{Notes and references}

1 M. A. Green, A. Ho-Baillie and H. J. Snaith, Nat. Photonics, 2014, 8, 506-514.

2 S. Brittman, G. W. P. Adhyaksa and E. C. Garnett, MRS Commun., 2015, 5, 7-26.

3 B. Saparov and D. B. Mitzi, Chem. Rev., 2016, 116, 45584596.

4 W. Nie, H. Tsai, R. Asadpour, A. J. Neukirch, G. Gupta, J. J. Crochet, M. Chhowalla, S. Tretiak, M. A. Alam and H. Wang, Science, 2015, 347, 522-526.

5 W. S. Yang, J. H. Noh, N. J. Jeon, Y. C. Kim, S. Ryu, J. Seo and S. II Seok, Science, 2015, 348, 1234-1237.
6 T. H. Han, S. Tan, J. Xue, L. Meng, J. W. Lee and Y. Yang, Adv. Mater., 2019, 1803515, 1-35.

7 D. Weber, Z. Naturforsch., B J. Chem. Sci., 1978, 1445, 14431445.

8 D. B. Mitzi, J. Chem. Soc., Dalton. Trans., 2001, 1, 1-12.

9 M. Daub, C. Haber and H. Hillebrecht, Eur. J. Inorg. Chem., 2017, 2017, 1120-1126.

10 M. Szafrański and A. Katrusiak, Phys. Rev. B - Condens. Matter Mater. Phys., 2000, 61, 1026-1035.

11 Y.-Y. Guo, J. A. McNulty, N. A. Mica, I. D. W. Samuel, A. M. Z. Slawin, M. Bühl and P. Lightfoot, Chem. Commun., 2019, 55, 9935-9938.

12 Z. Xiao, Z. Song and Y. Yan, Adv. Mater., 2019, 1803792, 122.

13 S. F. Hoefler, G. Trimmel and T. Rath, Monatshefte fur Chemie, 2017, 148, 795-826.

14 C. C. Stoumpos, C. D. Malliakas and M. G. Kanatzidis, Inorg. Chem., 2013, 52, 9019-9038.

15 W. Ke, C. C. Stoumpos and M. G. Kanatzidis, Adv. Mater., 2018, 1803230.

16 I. Chung, J. H. Song, J. Im, J. Androulakis, C. D. Malliakas, H. Li, A. J. Freeman, J. T. Kenney and M. G. Kanatzidis, J. Am. Chem. Soc., 2012, 134, 8579-8587.

17 X. Liu, Z. Yang, C. C. Chueh, A. Rajagopal, S. T. Williams, Y. Sun and A. K. Y. Jen, J. Mater. Chem. A, 2016, 4, 1793917945.

18 Z. Zhao, F. Gu, Y. Li, W. Sun, S. Ye, H. Rao, Z. Liu, Z. Bian and C. Huang, Adv. Sci., 2017, 4, 1700204.

19 M. D. Peel, S. P. Thompson, A. Daoud-Aladine, S. E. Ashbrook and P. Lightfoot, Inorg. Chem., 2012, 51, 6876-6889.

20 W. Travis, E. N. K. Glover, H. Bronstein, D. O. Scanlon and R. G. Palgrave, Chem. Sci., 2016, 7, 4548-4556.

21 R. D. Shannon, Acta Crystallogr., 1976, A32, 751-767.

22 C. C. Stoumpos, L. Frazer, D. J. Clark, Y. S. Kim, S. H. Rhim, A. J. Freeman, J. B. Ketterson, J. I. Jang and M. G. Kanatzidis, J. Am. Chem. Soc., 2015, 137, 6804-6819.

23 N. W. Thomas and A. Beitollahi, Acta Crystallogr., 1994, B50, 549-560.

24 C. C. Stoumpos, L. Mao, C. D. MAlliakas and M. G. Kanatzidis, Inorg. Chem., 2017, 56, 56-73.

25 J. Tian, D. B. Cordes, C. Quarti, D. Beljonne, A. M. Z. Slawin, E. Zysman-Colman and F. D. Morrison, ACS Appl. Energy Mater., 2019, 2, 5427-5437.

26 C. Michel, J. M. Moreau, G. D. Achenbach, R. Gerson and W. J. James, Solid State Commun., 1969, 7, 865-868.

27 S. C. Abrahams, J. M. Reddy and J. L. Bernstein, J. Phys. Chem. Solids, 1966, 27, 997-1012. 


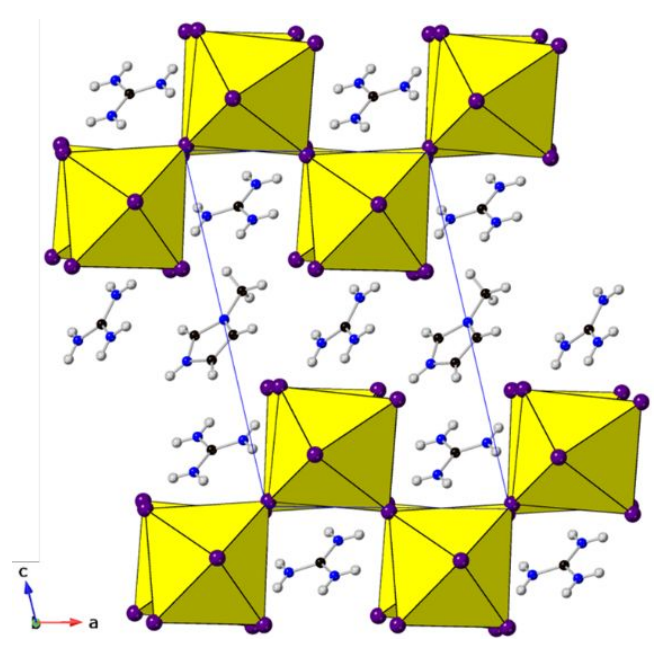

Two new hybrid tin iodide perovskites displaying unusual structural features mediated by ordering of organic moieties are presented 


\section{Unprecedented tin iodide perovskite-like structures featuring ordering of organic moieties}

Jason A. McNulty and Philip Lightfoot ${ }^{*} a$

${ }^{a}$ School of Chemistry and EaStChem, University of St Andrews, Fife, KY16 9ST, UK. E-mail:pl@st-andrews.ac.uk

\section{Supplementary Information}

\section{Synthesis}

Tin powder ( $\sim 325$ mesh, 99.8\% metals basis), hydroiodic acid (HI, 57\%, w/w aqueous solution stabilised with 1.5\% HPA), hypophosphorous acid $\left(\mathrm{H}_{3} \mathrm{PO}_{2}\right.$ (HPA), $50 \% \mathrm{w} / \mathrm{w}$ aqueous solution), 1,2,4triazole $\left(\mathrm{C}_{2} \mathrm{H}_{3} \mathrm{~N}_{3}, 99 \%\right)$ and 1-methyl imidazole $\left(\mathrm{C}_{4} \mathrm{~N}_{2} \mathrm{H}_{7}, 99 \%\right)$ were purchased from Alfa Aesar. Guanidinium carbonate $\left(\mathrm{C}_{2} \mathrm{H}_{10} \mathrm{~N}_{6} \mathrm{H}_{2} \mathrm{CO}_{3}, 99 \%\right)$ and diethyl ether $\left(\left(\mathrm{C}_{2} \mathrm{H}_{5}\right)_{2} \mathrm{O}, 99.5 \%\right)$ were purchased from Sigma Aldrich. All chemicals were directly used without further purification.

Both $(\mathrm{GuH})_{1.5}(\mathrm{Me}-\mathrm{ImH})_{0.5} \mathrm{SnI}_{4}$ and $(\mathrm{GuH})_{0.5}(\mathrm{TzH})_{0.5} \mathrm{SnI}_{3}$ were crystallised by a slow evaporation method.

For $(\mathrm{GuH})_{1.5}(\mathrm{Me}-\mathrm{ImH})_{0.5} \mathrm{SnI}_{4}\left(\left[\mathrm{C}\left(\mathrm{NH}_{2}\right)_{3}\right]_{1.5}\left[\mathrm{C}_{4} \mathrm{~N}_{2} \mathrm{H}_{7}\right]_{0.5} \mathrm{SnI}_{4}\right.$ : Tin powder $(237 \mathrm{mg}, 2 \mathrm{mmol})$ was dissolved in conc. HI $(5 \mathrm{ml})$ and HPA $(5 \mathrm{ml})$ with moderate heating. Once fully dissolved, guanidinium carbonate $(180 \mathrm{mg}, 2 \mathrm{mmol})$ and 1-methyl imidazole $(164 \mathrm{mg}, 2 \mathrm{mmol})$ were added and the solution allowed to cool for several days. A mixture of red crystals was obtained. These were filtered and washed with diethyl ether. Elemental analysis: (Anal. Calc. (\%) for $(\mathrm{GuH})_{1.5}(\mathrm{Me}-\mathrm{ImH})_{0.5} \mathrm{SnI}_{4}: \mathrm{C} 5.55 ; \mathrm{N} \mathrm{10.16}$; $\mathrm{H}$ 1.66. Found: $\mathrm{C} 6.36 ; \mathrm{N} 8.79 ; \mathrm{H} 1.68)$. The excess of $\mathrm{C}$ found in the sample and lower than expected $\mathrm{N}$ suggests a mixture of phases present consistent with the mixture of crystals obtained.

For $\mathrm{G}_{0.5} \mathrm{~T}_{0.5} \mathrm{SnI}_{3}\left(\left[\mathrm{C}\left(\mathrm{NH}_{2}\right)_{3}\right]_{0.5}\left[\mathrm{C}_{2} \mathrm{~N}_{3} \mathrm{H}_{4}\right]_{0.5} \mathrm{SnI}_{3}\right.$ : Tin powder $(237 \mathrm{mg}, 2 \mathrm{mmol})$ was dissolved in conc. HI $(5 \mathrm{ml})$ and HPA $(5 \mathrm{ml})$ with moderate heating. Once fully dissolved, guanidinium carbonate $(180 \mathrm{mg}$, $2 \mathrm{mmol}$ ) and 1,2,4-triazole (138 $\mathrm{mg}, 2 \mathrm{mmol}$ ) were added and the solution allowed to cool. Within days, small red crystals formed, these were left to grow in solution for several months before being filtered and washed with diethyl ether. Elemental analysis: (Anal. Calc. (\%) for $\mathrm{G}_{0.5} \mathrm{~T}_{0.5} \mathrm{SnI}_{3}: \mathrm{C} 3.19 ; \mathrm{N} \mathrm{7.44; \textrm {H }}$ 0.89. Found: C 3.31 ; N 7.57; H 0.88).

The synthesis of both $(\mathrm{GuH})_{1.5}(\mathrm{Me}-\mathrm{ImH})_{0.5} \mathrm{SnI}_{4}$ and $(\mathrm{GuH})_{0.5}(\mathrm{TzH})_{0.5}$ was carried out in air. HPA was used in the reaction to prevent oxidation of $\mathrm{Sn}^{2+}$ to $\mathrm{Sn}^{4+}$ while the crystals remained in solution. After filtration the crystals were stored under argon. In air, $(\mathrm{GuH})_{1.5}(\mathrm{Me}-\mathrm{ImH})_{0.5} \mathrm{SnI}_{4}$ oxidises within seconds with a clear colour change and evolution of $\mathrm{I}_{2}$. In $(\mathrm{GuH})_{0.5}(\mathrm{TzH})_{0.5} \mathrm{SnI}_{3}$ however, there is no evidence of an immediate colour change or evolution of $\mathrm{I}_{2}$. There does appear to be some decomposition after 30 minutes suggesting that $(\mathrm{GuH})_{0.5}(\mathrm{TzH})_{0.5} \mathrm{SnI}_{3}$ is more stable than the $3 \mathrm{D}$ perovskites $\mathrm{CsSnI}_{3}{ }^{1}$ and $\mathrm{MASnI}_{3}{ }^{2}$ but not as stable as $\mathrm{FASnI}_{3},{ }^{3}$ which is air stable for approximately $2 \mathrm{~h}$ before total decomposition after 1 day. 


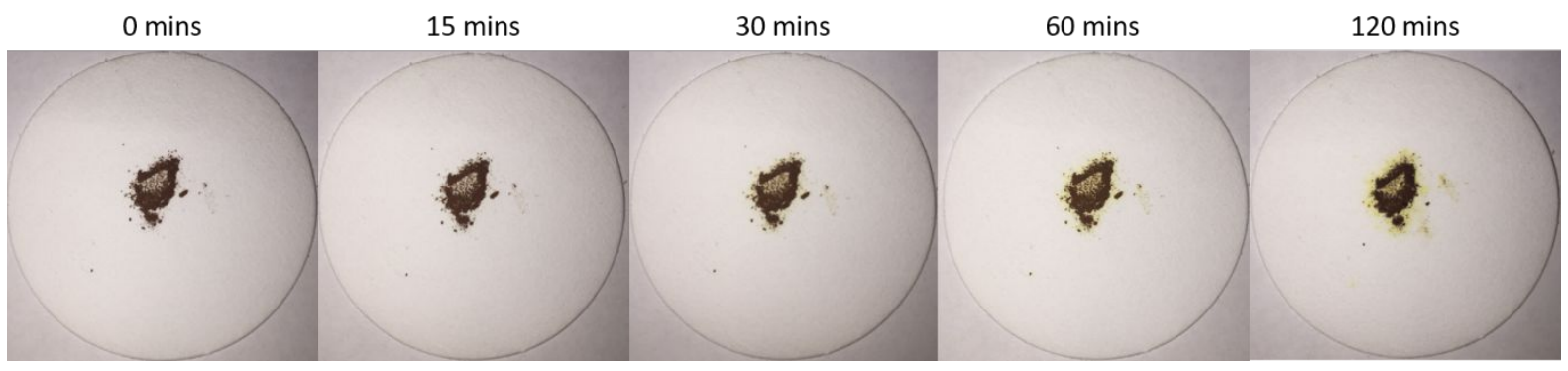

Figure S1 Powdered $(\mathrm{GuH})_{0.5}(\mathrm{TzH})_{0.5} \mathrm{SnI}_{3}$ at different exposure times to air.

\section{Characterisation}

Single Crystal data were collected at $173 \mathrm{~K}$ on a Rigaku SCX Mini diffractometer using Mo-K $\alpha$ radiation. Data were collected using CrystalClear (Rigaku). ${ }^{4}$ Structures were solved by direct methods and refined using SHELX-2014 incorporated in the WINGX program. ${ }^{6}$ Absorption corrections were performed semi-empirically from equivalent reflections on the basis of multi scans. Non-H atoms were refined anisotropically and hydrogen atoms were treated as riding atoms.

The bond length distortion of the $\mathrm{SnI}_{6}$ octahedra in each composition at $173 \mathrm{~K}$ was calculated using eq. $1,{ }^{7}$ where $d$ is the average Sn-I bond distance and $d_{\mathrm{n}}$ are the six individual bond distances. The bond angle variance of each octahedron from the ideal $90^{\circ}$ of an undistorted structure was calculated using eq. $2,{ }^{8}$ where $\theta_{\mathrm{i}}$ is the individual I-Sn-I angle.

$$
\begin{aligned}
& \Delta d=\left(\frac{1}{6}\right) \sum\left[\frac{d_{n}-d}{d}\right]^{2} \\
& \sigma^{2}=\sum_{i=1}^{12} \frac{\left(\theta_{i}-90\right)^{2}}{11}
\end{aligned}
$$


Table S1 Selected bond lengths $(\AA)$ and angles $\left(^{\circ}\right)$ derived from single crystal data collected at $173 \mathrm{~K}$.

\begin{tabular}{|c|c|c|c|c|c|c|}
\hline & \multicolumn{4}{|c|}{$(\mathrm{GuH})_{1.5}(\mathrm{Me}-\mathrm{ImH})_{0.5} \mathrm{SnI}_{4}$} & \multicolumn{2}{|c|}{$(\mathrm{GuH})_{0.5}(\mathrm{TzH})_{0.5} \mathrm{SnI}_{3}$} \\
\hline \multirow[t]{6}{*}{ Sn-I } & Sn1-I1 & $3.585(3)$ & $\mathrm{Sn} 2-\mathrm{I}^{2}$ & $3.502(2)$ & Sn-I3 & $3.562(1)$ \\
\hline & Sn1-I6 & $3.269(5)$ & Sn2-I & $3.462(9)$ & Sn-I2 & $3.544(1)$ \\
\hline & Sn1-I3 & $3.217(6)$ & $\mathrm{Sn} 2-\mathrm{I}$ & $3.325(5)$ & Sn-I1 & $3.442(1)$ \\
\hline & Sn1-I5 & $3.147(6)$ & $\mathrm{Sn} 2-\mathrm{I}^{\mathrm{T}}$ & $3.050(4)$ & Sn-I1 & $2.944(1)$ \\
\hline & Sn1-I4 & $3.104(4)$ & Sn2-I & $2.994(2)$ & $\mathrm{Sn}-\mathrm{I} 2$ & $2.937(1)$ \\
\hline & Sn1-I2 & $2.978(2)$ & $\mathrm{Sn} 2-\mathrm{I} \xi$ & $2.985(7)$ & Sn-I3 & $2.936(1)$ \\
\hline \multirow[t]{4}{*}{ BVS } & Sn 1 & 1.91 & $\operatorname{Sn} 2$ & 1.99 & $\mathrm{Sn}$ & 2.19 \\
\hline & I1 & 0.63 & $\mathrm{I} 2$ & 0.67 & $\mathrm{I} 1$ & 0.75 \\
\hline & $\mathrm{I} 3$ & 0.43 & I6 & 0.46 & $\mathrm{I} 2$ & 0.72 \\
\hline & & & & & $\mathrm{I} 3$ & 0.72 \\
\hline \multirow[t]{12}{*}{ I-Sn-I } & \multicolumn{2}{|l|}{$84.501(2)$} & \multicolumn{2}{|c|}{$81.549(2)$} & \multicolumn{2}{|l|}{$78.91(2)$} \\
\hline & \multicolumn{2}{|l|}{$84.525(2)$} & \multicolumn{2}{|c|}{$84.237(2)$} & \multicolumn{2}{|l|}{$79.00(2)$} \\
\hline & \multicolumn{2}{|l|}{$86.708(2)$} & \multicolumn{2}{|c|}{$87.948(2)$} & \multicolumn{2}{|l|}{$86.77(2)$} \\
\hline & \multicolumn{2}{|l|}{$88.362(2)$} & \multicolumn{2}{|c|}{$88.822(2)$} & \multicolumn{2}{|l|}{$88.24(2)$} \\
\hline & \multicolumn{2}{|l|}{$89.378(2)$} & \multicolumn{2}{|c|}{$89.108(2)$} & \multicolumn{2}{|l|}{$89.20(2)$} \\
\hline & \multicolumn{2}{|l|}{$90.763(2)$} & \multicolumn{2}{|c|}{$89.916(2)$} & \multicolumn{2}{|l|}{$89.48(2)$} \\
\hline & \multicolumn{2}{|l|}{$91.163(2)$} & \multicolumn{2}{|c|}{$91.222(2)$} & \multicolumn{2}{|l|}{$89.61(2)$} \\
\hline & \multicolumn{2}{|l|}{$91.823(1)$} & \multicolumn{2}{|c|}{$92.451(2)$} & \multicolumn{2}{|l|}{$90.42(2)$} \\
\hline & \multicolumn{2}{|l|}{$92.307(2)$} & \multicolumn{2}{|c|}{$92.594(2)$} & \multicolumn{2}{|l|}{$91.64(2)$} \\
\hline & \multicolumn{2}{|l|}{$93.366(2)$} & $93.34^{\prime}$ & & $91.89(2)$ & \\
\hline & $93.593(2)$ & & $93.68^{\circ}$ & & $94.11(2)$ & \\
\hline & $93.807(2)$ & & $94.33^{\circ}$ & & $112.45(2)$ & \\
\hline Sn-I-Sn & $159.205(2)$ & & 164.8 & & & \\
\hline & $159.809(2)$ & & 169.0 & & & \\
\hline & & & 172.8 & & & \\
\hline
\end{tabular}


Table S2 Hydrogen bond lengths $(\AA)$ and angles $\left(^{\circ}\right)$ for $(\mathrm{GuH})_{1.5}(\mathrm{Me}-\mathrm{ImH})_{0.5} \mathrm{SnI}_{4}$ at $173 \mathrm{~K}$.

\begin{tabular}{|c|c|c|c|c|}
\hline D-H...A & d(D-H) & $\overline{d(H \ldots A)}$ & $d(D \ldots A)$ & $<$ (DHA) \\
\hline $\mathrm{N}(1)-\mathrm{H}(1 \mathrm{~A}) \ldots \mathrm{I}(1) \# 3$ & 0.86 & 3.30 & $3.704(5)$ & 111.5 \\
\hline $\mathrm{N}(1)-\mathrm{H}(1 \mathrm{~A}) \ldots \mathrm{I}(6) \# 3$ & 0.86 & 3.01 & $3.776(6)$ & 148.9 \\
\hline $\mathrm{N}(1)-\mathrm{H}(1 \mathrm{~B}) \ldots \mathrm{I}(5) \# 4$ & 0.86 & 3.11 & $3.801(6)$ & 139.4 \\
\hline $\mathrm{N}(1)-\mathrm{H}(1 \mathrm{~B}) \ldots \mathrm{I}(6) \# 4$ & 0.86 & 3.29 & $3.880(6)$ & 127.8 \\
\hline $\mathrm{N}(2)-\mathrm{H}(2 \mathrm{~A}) \ldots \mathrm{I}(6) \# 3$ & 0.86 & 3.04 & $3.796(6)$ & 148.1 \\
\hline $\mathrm{N}(2)-\mathrm{H}(2 \mathrm{~B}) \ldots \mathrm{I}(1) \# 5$ & 0.86 & 3.04 & $3.853(6)$ & 158.9 \\
\hline $\mathrm{N}(3)-\mathrm{H}(3 \mathrm{~A}) \ldots \mathrm{I}(5) \# 4$ & 0.86 & 3.11 & $3.814(6)$ & 141 \\
\hline $\mathrm{N}(3)-\mathrm{H}(3 \mathrm{~B}) \ldots \mathrm{I}(1) \# 5$ & 0.86 & 3.10 & $3.899(6)$ & 156 \\
\hline $\mathrm{N}(4)-\mathrm{H}(4 \mathrm{~A}) \ldots \mathrm{I}(4) \# 6$ & 0.86 & 2.97 & $3.761(6)$ & 154.7 \\
\hline $\mathrm{N}(4)-\mathrm{H}(4 \mathrm{~B}) \ldots \mathrm{I}(8) \# 5$ & 0.86 & 2.90 & $3.734(5)$ & 164.1 \\
\hline $\mathrm{N}(5)-\mathrm{H}(5 \mathrm{~A}) \ldots \mathrm{I}(4) \# 2$ & 0.86 & 3.25 & $3.969(6)$ & 142.5 \\
\hline $\mathrm{N}(5)-\mathrm{H}(5 \mathrm{~A}) \ldots \mathrm{I}(5) \# 2$ & 0.86 & 3.32 & $3.711(5)$ & 110.8 \\
\hline $\mathrm{N}(5)-\mathrm{H}(5 \mathrm{~B}) \ldots \mathrm{I}(4) \# 6$ & 0.86 & 2.90 & $3.708(6)$ & 158 \\
\hline $\mathrm{N}(6)-\mathrm{H}(6 \mathrm{~A}) \ldots \mathrm{I}(2) \# 2$ & 0.86 & 3.22 & $3.863(7)$ & 133.5 \\
\hline $\mathrm{N}(6)-\mathrm{H}(6 \mathrm{~B}) \ldots \mathrm{I}(7)$ & 0.86 & 3.16 & $3.558(6)$ & 111.2 \\
\hline $\mathrm{N}(7)-\mathrm{H}(7 \mathrm{~A}) \ldots \mathrm{I}(6)$ & 0.86 & 3.01 & $3.678(5)$ & 136.2 \\
\hline $\mathrm{N}(7)-\mathrm{H}(7 \mathrm{~A}) \ldots \mathrm{I}(8)$ & 0.86 & 3.30 & $3.770(5)$ & 116.8 \\
\hline $\mathrm{N}(7)-\mathrm{H}(7 \mathrm{~B}) \ldots \mathrm{I}(7) \# 7$ & 0.86 & 2.85 & $3.660(6)$ & 158.7 \\
\hline $\mathrm{N}(8)-\mathrm{H}(8 \mathrm{~A}) \ldots \mathrm{I}(7) \# 7$ & 0.86 & 3.02 & $3.788(6)$ & 150.5 \\
\hline $\mathrm{N}(8)-\mathrm{H}(8 \mathrm{~B}) \ldots \mathrm{I}(3) \# 1$ & 0.86 & 2.92 & $3.732(5)$ & 158.2 \\
\hline $\mathrm{N}(9)-\mathrm{H}(9 \mathrm{~A}) \ldots \mathrm{I}(2) \# 2$ & 0.86 & 3.32 & $3.968(7)$ & 134.3 \\
\hline $\mathrm{N}(9)-\mathrm{H}(9 \mathrm{~B}) \ldots \mathrm{I}(3) \# 1$ & 0.86 & 3.10 & $3.878(7)$ & 151.3 \\
\hline $\mathrm{N}(9)-\mathrm{H}(9 \mathrm{~B}) \ldots \mathrm{I}(6) \# 2$ & 0.86 & 3.22 & $3.620(6)$ & 111.2 \\
\hline $\mathrm{N}(11)-\mathrm{H}(12) \ldots \mathrm{I}(4) \# 1$ & 0.86 & 3.14 & $3.694(6)$ & 124 \\
\hline $\mathrm{N}(11)-\mathrm{H}(12) \ldots \mathrm{I}(5) \# 2$ & 0.86 & 3.04 & $3.643(6)$ & 129.3 \\
\hline
\end{tabular}

Symmetry transformations used to generate equivalent atoms:
$\# 1-x+2,-y+1,-z$
$\# 2-x+1,-y+1,-z$
$\# 3-x+2,-y+2,-z+1$
$\# 4 x+1, y, z+1$
$\# 5-x+1,-y+2,-z+1$
$\# 6 x, y, z+1$
$\# 7 x+1, y, z$ 
Table S3 Hydrogen bond lengths $(\AA)$ and angles $\left(^{\circ}\right)$ for $(\mathrm{GuH})_{0.5}(\mathrm{TzH})_{0.5} \mathrm{SnI}_{3}$ at $173 \mathrm{~K}$.

\begin{tabular}{|c|c|c|c|c|}
\hline D-H...A & d(D-H) & d(H...A) & $\mathbf{d}(\mathrm{D} \ldots \mathrm{A})$ & $<$ (DHA) \\
\hline $\mathrm{N}(1 \mathrm{a})-\mathrm{H}(1 \mathrm{Aa}) \ldots \mathrm{I}(2) \# 2$ & 0.86 & 3.31 & $3.958(5)$ & 133.9 \\
\hline $\mathrm{N}(1 \mathrm{a})-\mathrm{H}(1 \mathrm{Aa}) \ldots \mathrm{I}(3) \# 2$ & 0.86 & 3.10 & $3.818(5)$ & 142.9 \\
\hline $\mathrm{N}(1 \mathrm{a})-\mathrm{H}(1 \mathrm{Ba}) \ldots \mathrm{I}(2) \# 5$ & 0.86 & 3.31 & $3.958(5)$ & 133.9 \\
\hline $\mathrm{N}(1 \mathrm{a})-\mathrm{H}(1 \mathrm{Ba}) \ldots \mathrm{I}(3) \# 5$ & 0.86 & 3.10 & $3.818(5)$ & 142.9 \\
\hline $\mathrm{N}\left(1^{\prime} \mathrm{b}\right)-\mathrm{H}\left(1^{\prime} 1 \mathrm{~b}\right) \ldots \mathrm{I}(1) \# 6$ & 0.86 & 3.28 & $3.958(18)$ & 138 \\
\hline $\mathrm{N}\left(1^{\prime} \mathrm{b}\right)-\mathrm{H}\left(1^{\prime} 1 \mathrm{~b}\right) \ldots \mathrm{I}(2) \# 3$ & 0.86 & 2.82 & $3.45(2)$ & 131.5 \\
\hline $\mathrm{N}\left(1^{\prime} \mathrm{b}\right)-\mathrm{H}\left(1^{\prime} 2 \mathrm{~b}\right) \ldots \mathrm{I}(1) \# 3$ & 0.86 & 3.28 & $3.958(18)$ & 138 \\
\hline $\mathrm{N}\left(1^{\prime} \mathrm{b}\right)-\mathrm{H}\left(1^{\prime} 2 \mathrm{~b}\right) \ldots \mathrm{I}(2) \# 6$ & 0.86 & 2.82 & $3.45(2)$ & 131.5 \\
\hline $\mathrm{N}(2 \mathrm{a})-\mathrm{H}(2 \mathrm{Aa}) \ldots \mathrm{I}(1)$ & 0.86 & 3.12 & $3.863(9)$ & 146.3 \\
\hline $\mathrm{N}(2 \mathrm{a})-\mathrm{H}(2 \mathrm{Ba}) \ldots \mathrm{I}(2) \# 6$ & 0.86 & 3.17 & $3.810(10)$ & 132.9 \\
\hline $\mathrm{N}\left(2^{\prime} \mathrm{b}\right)-\mathrm{H}\left(2^{\prime} 1 \mathrm{~b}\right) \ldots \mathrm{I}(2) \# 2$ & 0.86 & 3.00 & $3.62(3)$ & 130.8 \\
\hline $\mathrm{N}\left(2^{\prime} \mathrm{b}\right)-\mathrm{H}\left(2^{\prime} 1 \mathrm{~b}\right) \ldots \mathrm{I}(3) \# 2$ & 0.86 & 2.98 & $3.55(3)$ & 125.4 \\
\hline $\mathrm{N}\left(2^{\prime} \mathrm{b}\right)-\mathrm{H}\left(2^{\prime} 2 \mathrm{~b}\right) \ldots \mathrm{I}(1)$ & 0.86 & 3.12 & $3.79(3)$ & 136.7 \\
\hline $\mathrm{N}(4)-\mathrm{H}(4 \mathrm{~A}) \ldots \mathrm{I}(1)$ & 0.93 & 3.13 & $3.927(9)$ & 144.8 \\
\hline $\mathrm{N}(4)-\mathrm{H}(4 \mathrm{~A}) \ldots \mathrm{I}(2) \# 1$ & 0.93 & 3.01 & $3.664(9)$ & 128.7 \\
\hline $\mathrm{N}(5)-\mathrm{H}(5 \mathrm{~A}) \ldots \mathrm{I}(2) \# 7$ & 0.93 & 3.28 & $3.833(14)$ & 120.2 \\
\hline $\mathrm{N}(5)-\mathrm{H}(5 \mathrm{~A}) \ldots \mathrm{I}(3) \# 2$ & 0.93 & 3.07 & $3.823(14)$ & 139.6 \\
\hline $\mathrm{N}(5)-\mathrm{H}(5 \mathrm{~A}) \ldots \mathrm{I}(3) \# 7$ & 0.93 & 3.25 & $3.822(13)$ & 121.8 \\
\hline
\end{tabular}

Symmetry transformations used to generate equivalent atoms:
$\# 1 y, x,-z$
$\# 2 x-1 / 2,-y+1 / 2,-z+1 / 4$
$\# 3 x+1 / 2,-y+1 / 2,-z+1 / 4$
$\# 4-y+1,-x+1,-z+1 / 2$
\#5 $y+1 / 2,-x+3 / 2, z+1 / 4$
$\# 6 y+1 / 2,-x+1 / 2, z+1 / 4$

$\# 7 x, y+1, z$

Table S4 Distortion mode amplitudes for the $\mathrm{SnI}_{6}$ octahedra in $(\mathrm{GuH})_{0.5}(\mathrm{TzH})_{0.5} \mathrm{SnI}_{3}$ obtained from the ISODISTORT software suite ${ }^{9}$ compared to the aristotype $\mathrm{CsSnI}_{3}$ structure. $^{10}$

\begin{tabular}{lllll}
\hline Mode & Amplitude $(\mathbf{\AA})$ & Origin & $\mathbf{S , i}$ & $\boldsymbol{k}$-active \\
\hline$\Delta_{5}{ }^{a}$ & 1.704 & $(0,0,3 / 2)$ & 4,24 & $(0,0,1 / 4)$ \\
$\mathrm{R}_{3}{ }^{+}$ & 0.034 & $(-1 / 2,-1 / 2,0)$ & 2,6 & $(1 / 2,1 / 2,1 / 2)$ \\
$\mathrm{X}_{4}^{-}$ & 0.299 & $(0,0,1 / 2)$ & 2,6 & $(0,0,1 / 2)$ \\
$\mathrm{M}_{3}{ }^{+}$ & 0.077 & $(0,0,0)$ & 2,6 & $(1 / 2,1 / 2,0)$ \\
$\mathrm{M}_{3}{ }^{-}$ & 0.370 & $(-1 / 2,0,0)$ & 2,6 & $(1 / 2,1 / 2,0)$ \\
$\mathrm{T}_{5}$ & 0.459 & $(-1 / 2,0,-1 / 2)$ & 4,24 & $(1 / 2,1 / 2,1 / 4)$ \\
\hline
\end{tabular}

${ }^{a} \Delta_{5}$ is clearly the dominant distortion mode and is responsible for displacement of the iodide ligands leading to 
the extreme octahedral distortion observed.

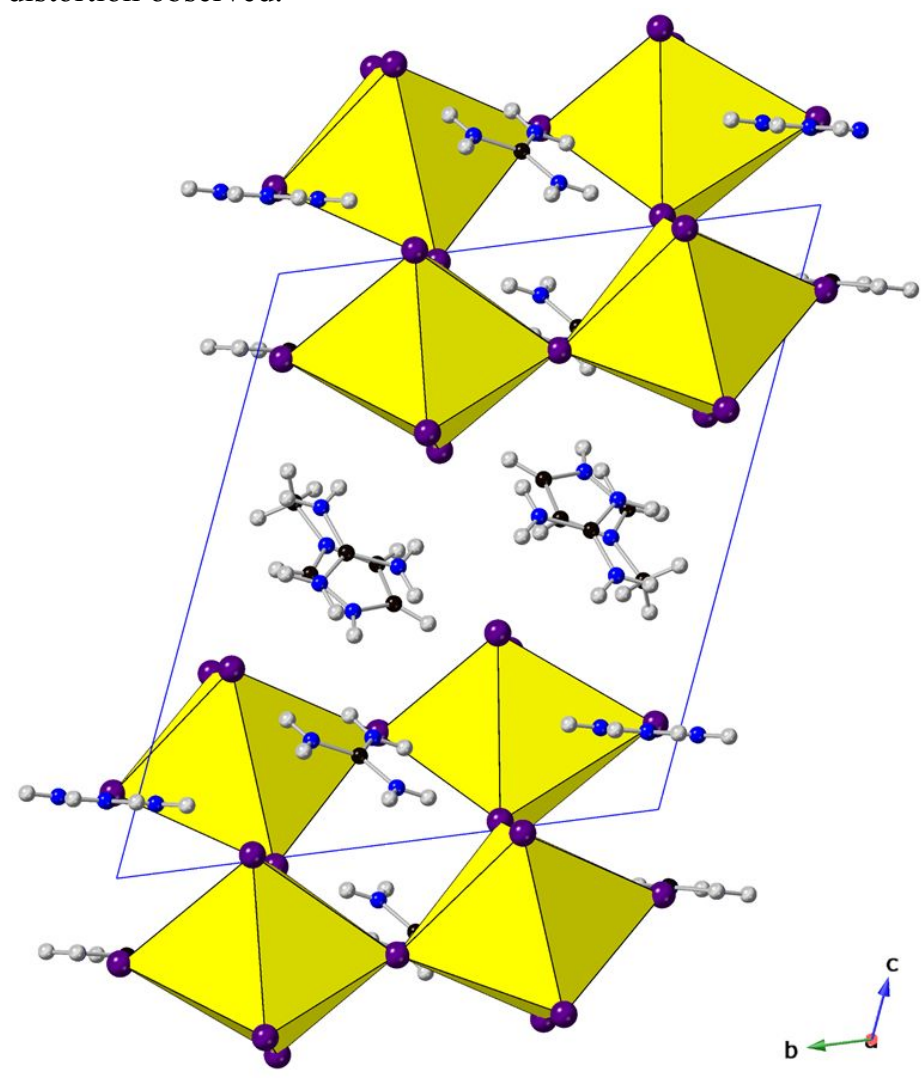

Figure S2 Crystal structure of $(\mathrm{GuH})_{1.5}(\mathrm{Me}-\mathrm{ImH})_{0.5} \mathrm{SnI}_{4}$ viewed along the $b$-axis highlighting the observed staggering of amines.<smiles>NC(N)=[NH2+]</smiles>

guanidinium

$(\mathrm{GuH})$<smiles>c1c[nH+]c[nH]1</smiles>

imidazolium

$(\mathrm{ImH})$<smiles>Cn1cc[nH+]c1</smiles>

1-methylimidazolium (Me-ImH)<smiles>C[NH3+]</smiles>

methylammonium

(MA)<smiles>c1n[nH]c[nH+]1</smiles>

1,2,4-triazolium ( $\mathrm{TzH})$<smiles>NC=[NH2+]</smiles>

formamidinium (FA)

Figure S3 Structures of organic moieties used in this work (top) and previously in literature (bottom). 


\section{References}

1. J. Jiang, C. K. Onwudinanti, R. A. Hatton, P. A. Bobbert and S. Tao, J. Phys. Chem. C, 2018, 122, 17660-17667.

2. J. Xiang, K. Wang, B. Ziang and X. Cui, J. Chem. Phys., 2018, 148, 124111.

3. C. C. Stoumpos, C. D. Malliakas and M. G. Kanatzidis, Inorg. Chem., 2013, 52, 9019-9038.

4. Rigaku, 2014, CrystalClear, Rigaku Corporation, Tokyo, Japan.

5. G. M. Sheldrick, Acta Crystallogr., 2015, C71, 3.

6. L. J. Farrugia, J. Appl. Crystallogr., 2012, 45, 849.

7. M. W. Lufaso and P. M. Woodward, Acta Crystallogr., 2004, B60, 10.

8. K. Robinson, G. V. Gibbs and P. H. Ribbe, Science, 1971, 172, 567.

9. B. J. Campbell, H. T. Stokes, D. E. Tanner and D. M. Hatch, J. Appl. Cryst., 2006, 39, 607614.

10. I. Chung, J. H. Song, J. Im, J. Androulakis, C. D. Malliakas, H. Li, A. J. Freeman, J. T. Kenney and M. G. Kanatzidis, J. Am. Chem. Soc., 2012, 134, 8579-8587. 